\title{
Characterisation of Micrometeorological Parameters in Ecuadorian Highland
}

\author{
Nelly Perugachi1 ${ }^{1,2}$, Cecilia Limaico ${ }^{1,2}$, Susana Cocha1, Arquímides Haro ${ }^{1,2}$ \\ ${ }^{1}$ Escuela Superior Politécnica de Chimborazo, Riobamba, Ecuador \\ ${ }^{2}$ Universidad Nacional de Chimborazo, Riobamba, Ecuador \\ Email: nperugachi@yahoo.es, aharo@espoch.edu.ec
}

How to cite this paper: Perugachi, N., Limaico, C., Cocha, S. and Haro, A. (2017) Characterisation of Micrometeorological Parameters in Ecuadorian Highland. At mospheric and Climate Sciences, 7, 455-462. https://doi.org/10.4236/acs.2017.74033

Received: July 14, 2017

Accepted: September 10, 2017

Published: September 13, 2017

Copyright (c) 2017 by authors and Scientific Research Publishing Inc. This work is licensed under the Creative Commons Attribution International License (CC BY 4.0).

http://creativecommons.org/licenses/by/4.0/

(c) (i) Open Access

\begin{abstract}
The interaction among air and soil affects the dynamic in the atmospheric boundary layer, this research seeks to describe this variation in small scale, in the Ecuadorian Highlands Regions and the variations produced due to its elevation and geographical position, using as base the Van Ulden and Hostlang (1985) models. From this research, there was a conclusion that the zone has strong fluids of sensitive heat and superficial heat with small variations in the latent fluid heat. Besides, there were significant variations of the Obukov length between 17:00 and 19:00, when the sunset occurs, producing a thermal inversion that modifies the atmospheric dynamic state, these results average vary during the day hours and are regulars in the daily and monthly average, in the research year, given the zone geographical position. The meteorological data utilized were taken from the meteorological station from Universidad Nacional de Chimborazo located in the Ecuadorian Highlands.
\end{abstract}

\section{Keywords}

Micrometeorology, Atmospheric Parameters, Ecuadorian Highlands, Air-Soil Interaction

\section{Introduction}

The atmosphere works as a safety barrier, without it; temperature would reach $+75^{\circ} \mathrm{C}$ during the day and $-130^{\circ} \mathrm{C}$ below 0 at night, it is made up from a gases mixture that surround the planet with thick concentric layers and variable densities. The atmosphere base is in contact with the land's surface and its irregularities such as the continent's protrudes [1]. The boundary layer or superficial layer is the lowest layer of the atmosphere, where the atmospheric turbulence is created by thermal or mechanic imbalances, produces an increase in air chaotic 
movements, and it facilitates the diffusion phenomenon, energy and matter transport [2] [3].

The atmosphere is not a closed system, it produces exchanges between various elements and has related properties according to their physical state and chemical composition. Internal procedures and external interactions maintain or modify the atmospheric dynamic [4] [5] [6]. Gases that made up the atmosphere, are well mixed, but it is not physically constant because it has some significant temperature and pressure variations, in relation with the height above sea level [7], phenomenon that affects the Ecuadorian Highland, whose height fluctuates between $1000 \mathrm{~m}$ a.s.l and $6310 \mathrm{~m}$ a.s.l, with an average surrounding $2500 \mathrm{~m}$ a.s.l, and it is located in the Equatorial zone, a length around zero degrees.

Most of the atmospheric phenomenon occur in the troposphere, the atmospheric lowest layer, and particularly in the atmospheric boundary layer, superficial troposphere sub layer, where important dynamic processes are carried out. These dynamic processes are given because of the mechanical turbulence development, which is related to the friction between air and the solid surface and the convective turbulence, produced by the heat fluid among soil and air, the result of the soil heating during day hours [8]. Natural processes that occur in atmosphere are turbulent, which means, a nonlinear system, being a reason for the development several models that describe its dynamic [9]-[14].

The main objective of this research was to study the atmospheric micro dynamic in the Ecuadorian plateau, for establishing the characteristics according to the produced effects because of the height and geographical position in the zone, by the utilization of proposed methods by Van Ulden and Hostlag in 1985 [3], which are adjusted to air physic properties in the zone, Haro A. et al. (2014), using meteorological data measured at Universidad Nacional de Chimborazo station, located in Riobamba with a geographic position $1^{\circ} 38^{\prime}$ and $1^{\circ} 4^{\prime}$ south latitude, $78^{\circ} 39^{\prime}$ y $78^{\circ} 40^{\prime}$ west longitude, highland at $2754 \mathrm{~m}$ a.s.l located in the Ecuadorian plateau.

\section{Material and Methods}

Using proposed methods by Van Ulden and Hostlag [3], a study of superficial fluids has been developed in the boundary atmospheric surface. It is considered that when an air mass circulates over a surface and goes to another one with different characteristics, its physical properties change [15] [16].

The balance energy equation in simplified form is given by Equation (1):

$$
R_{N}=Q_{H}+Q_{E}+Q_{G}
$$

where: $R_{N}$ net radiation flux, $Q_{H}$ sensible heat flux, $Q_{E}$ latent heat flux and $Q_{G}$ stored heat flux in soil, Equation (2).

Where: net radiation fluid $R_{N}$, sensitive heat fluid $Q_{H}$, latent heat fluid $Q_{E}$ and heat fluid stored in the soil $Q_{G}$, Equation (2). 


$$
Q_{G}=a_{e} \cdot R_{N}
$$

With $a_{e}$, a constant equal to 0.1 in rural areas and 0.3 for urban areas, proposed by Doll D., Ching J. K. S. and Kaneshire J. [8].

Sensitive heat is given by Equation (3) [7].

$$
Q_{H}=\left[\frac{(1-a)+S}{1+S}\right] R_{N}(1-a)-\xi
$$

where $\xi$ is a constant equal to $20 \mathrm{~W} \cdot \mathrm{m}^{-2}$ and the parameter $S$ is defined by Equation (4).

$$
S=\exp [0.055(T-279)]
$$

Net radiation can be parameterized according Equation (5), based on albedo $A$, solar elevation angle $\theta$, cloudiness fraction $N$, flux radiation incident $Q$ and air temperature $T$.

$$
R_{N}=\frac{(1-A) Q+c_{1} T^{6}-\sigma T^{4}+c_{2} N}{1+c_{3}}
$$

with

$$
\begin{aligned}
& \sigma=5.67 \times 10^{-8} \mathrm{~W} \cdot \mathrm{m}^{-2} \cdot \mathrm{K}^{-4} \text { it is the Stefan-Boltzmann constant. } \\
& c_{1}=5.31 \times 10^{-13} \mathrm{~W} \cdot \mathrm{m}^{-2} \cdot \mathrm{K}^{-6} \mathrm{y} c_{2}=60 \mathrm{~W} \cdot \mathrm{m}^{-2} . \\
& A=0.185\left(1-\exp \left(-\frac{h}{100}\right)\right)
\end{aligned}
$$

With $h$ humidity, the $c_{3}$ parameter is given by the formula:

$$
\begin{gathered}
c_{3}=\frac{0.38(1-\alpha) S+1}{S+1} \\
Q=\left(a_{1} \operatorname{sen} \phi+a_{2}\right)\left(1-b_{1} N^{b_{2}}\right)
\end{gathered}
$$

$a_{1}=990 \mathrm{~W} \cdot \mathrm{m}^{-2}$

$a_{2}=-30 \mathrm{~W} \cdot \mathrm{m}^{-2}$

$b_{1}=0.75$

$b_{2}=3.4$

With solar elevation, $\phi$, it can be calculated according to latitude function, and longitude to the studied zone and the Julian day [3].

The cloudiness is approximately determined with Equation (13).

$$
N=\left(1-\frac{b_{1} * Q}{a_{1} \operatorname{sen} \phi+a_{2}}\right)^{1 / b_{2}}
$$

The kinetic energy for the atmospheric turbulent is given by the Equation (9) [10] [11] [12].

$$
\frac{\partial\left(q^{2} / 2\right)}{\partial t}=\frac{g}{\vartheta}\left(\overline{w^{\prime} \vartheta^{\prime}}\right)+\frac{\partial U}{\partial Z}\left(\overline{w^{\prime} u^{\prime}}\right)-\varepsilon-\frac{\partial}{\partial Z}\left(\overline{\frac{w^{\prime} q^{\prime}}{2}}+\frac{\overline{w^{\prime} p^{\prime}}}{\ell}\right)
$$

The left term represents the total energy fluid, while the first right term represents the thermal energy fluctuation, the second term represents the me- 
chanical energy fluctuation, the third one the energy dissipation because of the friction effect and the fourth one, the term of the energy fluid that mixes the transport and pressure transport.

Obukhov' lenght $(L)$ is determined by Equation (9), where thermal and mechanical energy are balanced.

$$
\frac{(g / \vartheta)\left(\overline{w^{\prime} \vartheta^{\prime}}\right)}{(\partial U / \partial Z)\left(\overline{w^{\prime} u^{\prime}}\right)}=1
$$

According to the similarity theory of the low atmosphere, $\overline{w^{\prime} u^{\prime}}=\mu^{2}{ }_{*} y(\partial U / \partial Z)=\mu_{*} / K Z$, where $u_{*}=U(z) K / \log \left(z / z_{0}\right)$ friction velocity, with $U(z)$ wind speed to a height $z$ and $z_{0}$ of roughness height that can be found in charts [9], $Q_{H}=C_{p} \rho T \overline{w^{\prime} \vartheta^{\prime}}$ and $K$ the constant Van Karmans, $C_{p}$ specific air heat and $\rho$ air density that adjusts to the height through Equation (12) [14]. Replacing in Equation (6) and considering $Z=L$, the Obukhov length, it is described as:

$$
L=-\frac{\mu_{*}^{3} C_{p} \rho T}{K g Q_{H}}
$$

The parameter $L$ is considered surface and can be calculated with meteorological measurements (wind speed, temperature, pressure, net radiation, humidity) equation that is used as an indicator of the dynamic state of the atmosphere [3].

$$
\rho=\left(\frac{P_{o}}{P}\right) \frac{353.44}{T+273.15}
$$

The dynamic state is evident when a plot of land is moved upward, if it does not suffer an alteration with height, it means, if the external forces of the surrounding plots of land do not act, so; the atmosphere is considered as neutral or adiabatic; if the forces act and the small air portion is moved upward, it is said that is non-stable, but if the external forces tend to make the plot of land to go back to the initial position, then the atmosphere is in stable conditions.

Quantitatively, stability can be measured with Obukhov's length.

If $L<0$ is unstable

If $L>0$ is stable

If $L \pm \infty$ is neutral or stable

Depending on the fluctuation degree of mechanic or thermic energy, $L$ is negative when the thermic energy is positive (soil transfers heat to atmosphere) and positive when the opposite occurs, when this fluctuations ten to give a $L$ large number (positive o negative) it is said that the is neutral or adiabatic [10] [11].

\section{Results and Discussion Results and Discussion}

This research seeks characterize the micro-meteorological parameters variation, as a function of physical and meteorological parameters, according to Ecuadorian Highlands regions. For this, a software in MATLAB has been developed, based on the purpose of Van Ulden and Hostlang, which determines some pa- 
rameters such as: Obukhov's length, superficial heat fluids, sensitive and latent, friction speed and net radiation, which characterize the micro dynamic boundary atmospheric zone layer.

Table 1 presents annual averages, minimums, and maximums, of the meteorological variables measured in the research zone, where the height effects in temperature and pressure can be noticed, they decrease considerably according to the sea level, in the position that is the research zone (zero latitude). The results indicate strong radiation intensities with low air temperatures, which will produce temperature changes, specifically during day hours.

Table 2 presents the average, minimum, and maximum from the micrometeorological variables studied, where small variations where observed among latent heat fluid, sensitive and superficial, with a major fluctuation in the sensitive heat fluid, which varies between -27.19 to $359,76 \mathrm{~W} / \mathrm{m}^{2}$, the same occurs with Obukhov length which takes values among -6732.61 to $31020.98 \mathrm{~m}$, which indicates the strong energy fluctuations that occur between Earth and atmosphere, variables such as net radiation suffer a decrease in the found values regarding to the incident radiation due to the reflected radiation and the friction speed is characterized by maintaining values that fluctuate a small range from 0 until $1.10 \mathrm{~m} / \mathrm{s}$.

Figure 1 represents the variation of the thermal energy and net average radiation, an hour from a year (2015) they have been determined according to the researches by Van Ulden y Hostlag, with an important presence of sensitive and superficial heat fluid, due to the height and geographical position, a strong interaction between earth surface and superficial atmospheric air is produced, which is represented in the high values of the sensitive energy.

Figure 2 represents the speed variation of the hour average friction, in the

Table 1. Average, maximum and minimum methereological parameters from the year 2015 in Riobamba city.

\begin{tabular}{cccccc}
\hline & $\begin{array}{c}\text { Temperature } \\
\left({ }^{\circ} \mathrm{C}\right)\end{array}$ & Humidity \% & $\begin{array}{c}\text { Pressure } \\
(\mathrm{mB})\end{array}$ & $\begin{array}{c}\text { Radiation Incident } \\
\left(\mathrm{W} / \mathrm{m}^{2}\right)\end{array}$ & $\begin{array}{c}\text { Wind Speed } \\
(\mathrm{m} / \mathrm{s})\end{array}$ \\
\hline Average & 13.55 & 76.47 & 731.54 & 224.39 & 1.39 \\
Minimum & 3.86 & 20.74 & 726.39 & 0.00 & 0.00 \\
Maximum & 24.87 & 99.67 & 735.91 & 1276.87 & 7.95 \\
\hline
\end{tabular}

Data weather station of the air quality of the UNACH project.

Table 2. Average, maximum and minimum micrometeorological parameters from the year 2015 from Riobamba city.

\begin{tabular}{ccccccc}
\hline & $\begin{array}{c}\text { Sensible } \\
\text { Heat }\left(\mathrm{W} / \mathrm{m}^{2}\right)\end{array}$ & $\begin{array}{c}\text { Latent Heat } \\
\left(\mathrm{W} / \mathrm{m}^{2}\right)\end{array}$ & $\begin{array}{c}\text { Surface } \\
\text { Heat } \\
\left(\mathrm{W} / \mathrm{m}^{2}\right)\end{array}$ & $\begin{array}{c}\text { Net } \\
\text { Radiation } \\
\left(\mathrm{W} / \mathrm{m}^{2}\right)\end{array}$ & $\begin{array}{c}\text { Friction } \\
\text { Speed } \\
(\mathrm{m} / \mathrm{s})\end{array}$ & $\begin{array}{c}\text { Length of } \\
\text { Obukov } \\
(\mathrm{m})\end{array}$ \\
\hline Average & 44.14 & 44.17 & 37.84 & 126.15 & 0.21 & 4.12 \\
Minimum & -27.19 & 11.35 & -6.29 & -20.98 & 0.00 & -6732.61 \\
Maximum & 359.76 & 230.27 & 252.87 & 842.90 & 1.10 & 31020.98 \\
\hline
\end{tabular}




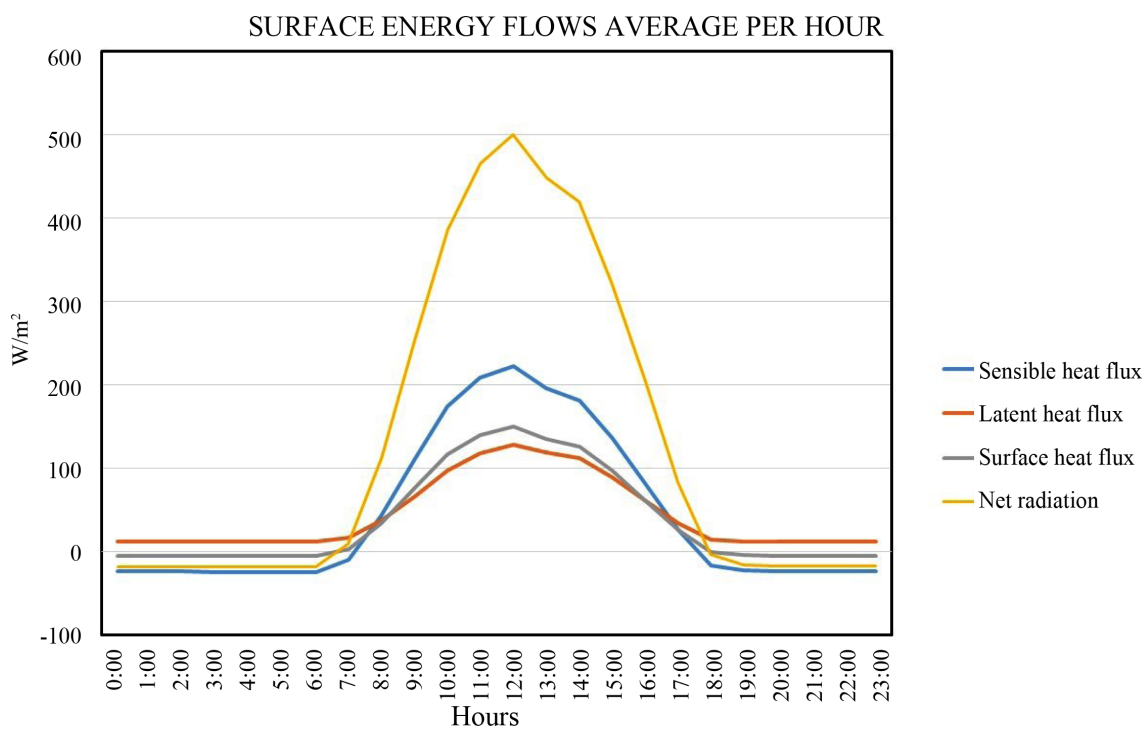

Figure 1. Sensitive heat fluids, latent heat, surface heat and net radiation, average per hour of the year 2015.

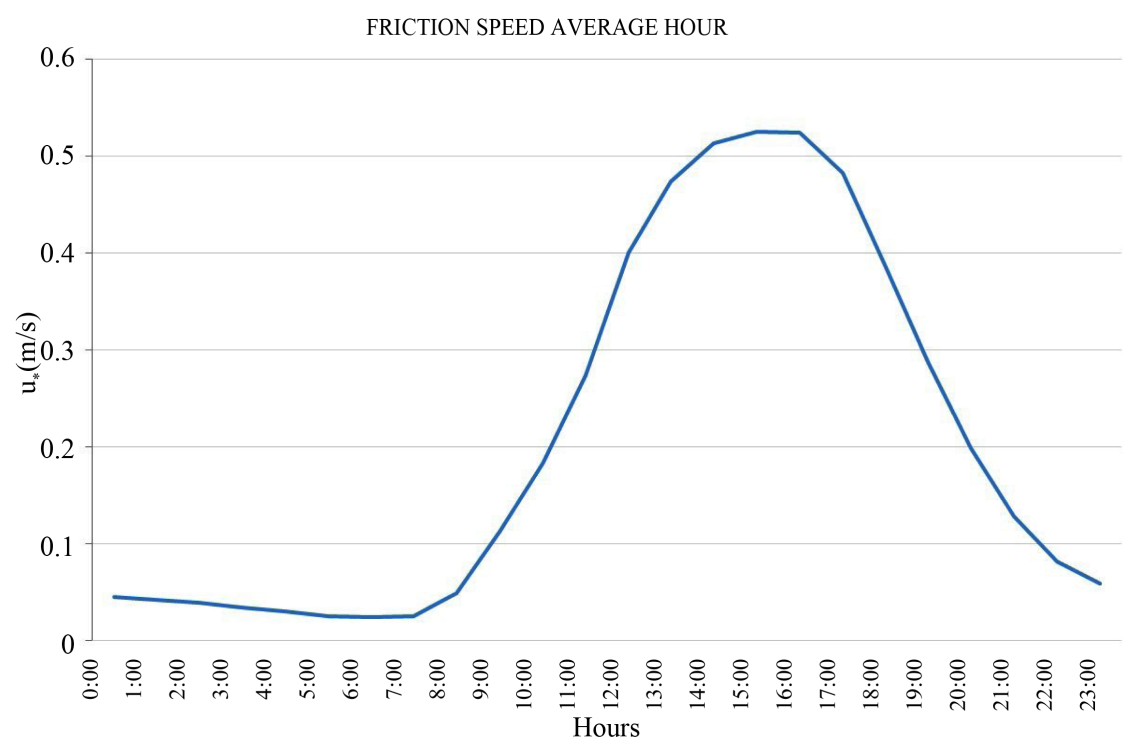

Figure 2. Average friction speed hour of the year 2015.

research year, with a tendency to ascend at midday and to decrease at night, being a regular behavior through the year due to the geographical position.

Figure 3 reflects the Obukhov length performance, an average hour in the research year, which presents a regular performance in different hours, with a strong variation between 17:00 and 19:00 during the sunset, which produces a thermal reversal, modifying the dynamic atmospheric state.

\section{Conclusion}

The variation of the regular meteorological parameters is determined during the year, with significant variations through the day, whose height and geographical 


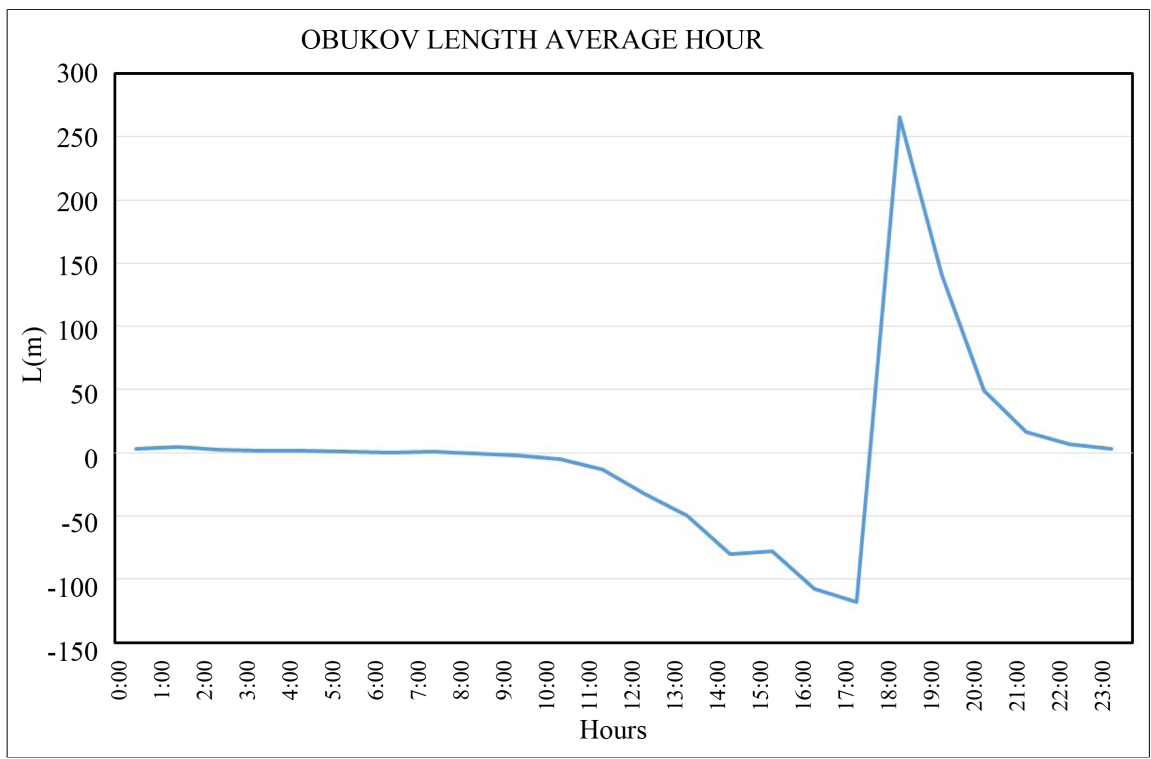

Figure 3. Length of Obukov average hour of year 2015.

position effects are specifically noticed in the temperature with a $13.55^{\circ} \mathrm{C}$ average and a pressure with a $731.54 \mathrm{mB}$ average, these are small according to the results above sea level a.s.l in those latitudes, where micrometeorological variables calculated with the model, present regular performances throughout the year, similar to the meteorological conditions, variations are presented mostly during the day, with significant variations in thermal energy fluids, notice the height effects and geographical position with a high sensitive heat fluid. Besides, Obukhov's length presents a regular performance through the year with significant variations between 17:00 and 19:00, where clearly a thermal reversal is presented which changes the atmospheric dynamic state.

\section{References}

[1] Rodríguez, R., et al. (2004) Meteorología y Climatología. [Meteorology and Climatology] FECYT (Fundación Española para la Ciencia y la Tecnología), Madrid.

[2] Pasquill, F. and Smith, F.B. (1983) Atmospheric Diffusion. Ellis Horwood Limited, Chichester, UK.

[3] Van Ulden, H. (1985) Estimation of Atmospheric Boundary Layer Parameters for Diffusion Applications. Journal of Applied Meteorology and Climatology, 24, 1196-1207.

[4] Kiely, G. (1999) Ingeniería Ambiental. Tomo II y III, McGRAW-HILL, Spain.

[5] Mankin, M. (2011) Atmospheric Dynamics. Cambridge University Press, Vol. 1, London, England.

[6] Amanda, H., et al. (2006) Applied Atmospheric Dynamics. John Wiley and Sons, England.

[7] Haro, A., et al. (2014) Thermal Flows in the Surface Atmosphere of the Riobamba City. Atmospheric and Climate Sciences, 4, 679-684. https://doi.org/10.4236/acs.2014.44061 
[8] Doll, D., Ching, J.K.S. and Kaneshire, J. (1985) Parametrization of Surfaces Heating for Soli and Concrete Using Net Radiation Data. Boundary Layer Meteorology, 32, 351-372. https://doi.org/10.1007/BF00122000

[9] Cohen, A., et al. (2015) A Review of Planetary Boundary Layer Parameterization Schemes and Their Sensitivity in Simulating Southeastern U.S. Cold Season Severe Weather Environments. Weather and Forecasting, 30, 591-612.

[10] Businger, J.A., et al. (1971) Flux-Profile Relationships in the Atmospheric Surface Layer. Journal of the Atmospheric Sciences, 28, 181-189. https://doi.org/10.1175/1520-0469(1971)028<0181:FPRITA >2.0.CO;2

[11] Rodríguez, D., et al. (2015) Variación de la estabilidad y altura de la capa de mezcla en la ciudad de pinar del río: Su relación con condiciones sinópticas. [Stability and Change in Mixing in City of Pinar Del Rio: It's Relationship with Synoptic Conditions] Revista Brasileira de Meteorología, 30, 1-15.

https://doi.org/10.1590/0102-778620140014

[12] Recalde, G., et al. (2014) Predictability of December-April Rainfall in Coastal and Andean Ecuador. Journal of Applied Meteorology and Climatology, 1471-1493.

[13] EPA AEROMOD (2004) Description of Model Formulation. EPA-454/R-03-004, Office of Air Quality Planning and Standards, 91.

[14] Desmond, C.J. and Watson, S. (2014) A Study of Stability Effects in Forested Terrain. Journal of Physics: Conference Series, 555, 1-17.

[15] Marks, D., et al. (2007) Comparing Simulated and Measured Sensible and Latent Heat Fluxes over Snow under a Pine Canopy to Improve an Energy Balance Snowmelt Model. Journal of Hydrometeorology, 9, 1506-1522.

https://doi.org/10.1175/2008JHM874.1

[16] Longob, A. and Villani, P. (2013) The Use of Micrometeorological Data to Identify Significant Variables in Evapotranspiration Modelling. Procedia Environmental Sciences, 19, 267-274. 